\title{
Large gastric heterotopia presenting as an obstructing duodenal mass
}

Gastric heterotopia is an ectopic lesion found throughout the gastrointestinal tract. The classic endoscopic appearance of gastric heterotopia is raised, salmonred mucosal patches or clusters of nodules above normal duodenal mucosa, ranging in size from $3 \mathrm{~mm}$ to $10 \mathrm{~mm}$ [1]. Large polypoid gastric heterotopia of the duodenum, defined as being greater than $2.5 \mathrm{~cm}$, is rare and clinical relevance has only been described on one other occasion [2]. We report the first published case of a large polypoid gastric heterotopia of the duodenum causing obstructive symptoms and diagnosed by endoscopy.

A 21-year-old woman was evaluated in October 2006 for complaints of dyspepsia, nausea, and vomiting. She was initially treated with lansoprazole. By February 2007, the patient developed early satiety, inability to tolerate solid foods, and lost $9 \mathrm{~kg}$ (20 lb) in weight. An upper gastrointestinal series noted narrowing of the second part of the duodenum. An esophagogastroduodenoscopy (EGD) demonstrated a single, pedunculated polypoid mass in the duodenum with the base originating near the major papilla, measuring over $4 \mathrm{~cm}$ ( $\bullet$ Fig. 1 ). Histological findings were consistent with gastric heterotopia.

A modified abdominal computed tomography (CT) scan with three-dimensional reconstruction demonstrated a $4.5 \times 2.5 \mathrm{~cm}$ polypoid mass with a broadbased attachment along the posterior aspect of the second part of the duodenum. Piecemeal resection was attempted on two subsequent EGDs with approximately $50 \%$ of the lesion excised ( Fig. 2 and 3 ). However, only temporary symptomatic relief was achieved. The patient underwent surgical resection with complete symptom resolution.

Gastric heterotopia presenting as a large polypoid mass is a rare finding. Clinically significant lesions are typically found in the jejunum and ileum [1,3-5]. There has only been one reported case of symptomatic, duodenal gastric heterotopia since 1927 [2]. The present case illustrates a rare, large polypoid lesion of gastric heterotopia causing obstructive symptoms in a young woman. Although endoscopic

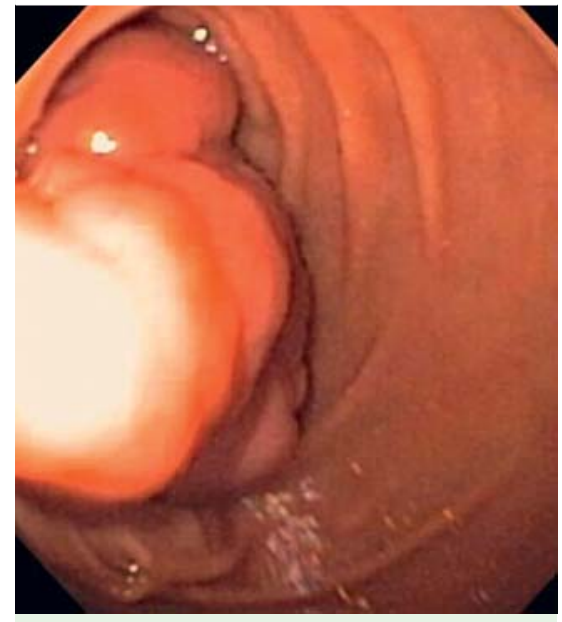

Fig. 1 Pedunculated, polypoid mass causing obstruction in the second portion of the duodenum on initial upper endoscopy.

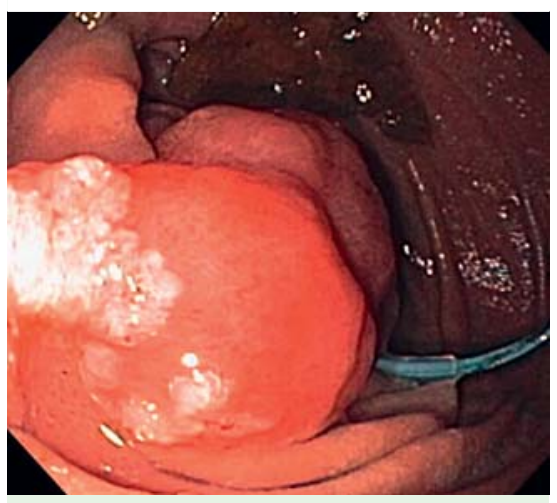

Fig. 2 The polypoid mass following piecemeal resection.

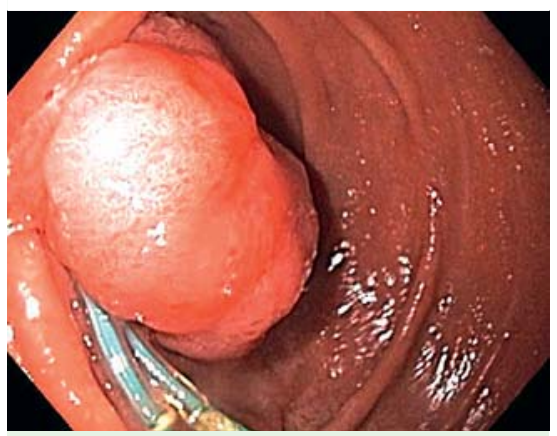

Fig. 3 Residual gastric heterotopia following two attempts at piecemeal resection and detachable snares.

treatment with piecemeal resection was unsuccessful for our patient, it remains a potential therapeutic option.
Endoscopy_UCTN_Code_CCL_1AB_2AZ_3AB

Competing interests: The views expressed in this article are those of the authors and should not be consumed to represent those of the U. S. Department of Defense, or the U.S. Department of the Army.

\section{R. K. Fincher ${ }^{1}$, M. Donovan ${ }^{2}$}

1 D. D. Eisenhower Army Medical Center, Fort Gordon, and Medical College of Georgia, Augusta, Georgia, USA

2 D. D. Eisenhower Army Medical Center, Fort Gordon, Georgia, USA

\section{References}

1 Mann NS, Mann SK, Rachut E. Heterotopic gastric tissue in the duodenal bulb. J Clin Gastroenterol 2000; 30 (3): 303-306

2 Cynn WS, Rickert RR. Heterotopic gastric mucosal polyp in the duodenal bulb associated with congenital absence of the gallbladder. Am J Gastroenterol 1973; 60: 171 177

3 Lambert MP, Heller DS, Bethel C. Extensive gastric heterotopia of the small intestine resulting in massive gastrointestinal bleeding, bowel perforation, and death: report of a case and review of the literature. Pediatr Dev Pathol 2000; 3 (3): 277-280

4 Khan MJ, Mullerat P, Desai A. A polypoid gastric heterotopia of jejunum diagnosed by capsule endoscopy. J Coll Physicians Surg Pak 2009; 19: 661 -662

5 Omotosho PA, Varnholt H, Tirabassi MV et al. Giant polypoid gastric heterotopia of the jejunum presenting with intermittent intussusceptions. J Laparoendosc Adv Surg Tech A 2007; 17 (2): 249-251

Bibliography

DOI $10.1055 / \mathrm{s}-0030-1256452$

Endoscopy 2011; 43: E246

(c) Georg Thieme Verlag KG Stuttgart · New York . ISSN 0013-726X

\section{Corresponding author}

\section{R. K. Fincher, MD, FACP, FACG}

D. D. Eisenhower Army Medical Center

Fort Gordon

Georgia 30905

USA

Fax: +706-787-2409

keithfincher@comcast.net 